\title{
HACIA UN MAPA DE LA "VIOLENCIA EN EL FÚTBOL": ACTORES, DINÁMICAS, RESPUESTAS PÚBLICAS Y DESAFÍOS EN EL CASO DE ARGENTINA
}

\author{
Diego Murzi \\ Instituto de Altos Estudios en Ciencias Sociales, Universidad Nacional de \\ San Martín - Conicet, Argentina \\ diegomurzi@gmail.com \\ Fernando Segura Millan Trejo \\ Centro de Investigación y Docencia Económicas, México \\ Universidad Federal de Goiás, Brasil \\ fernando.segura@cide.edu
}

\section{RESUMEN}

Este artículo analiza un corpus de "episodios de violencia" en el fútbol profesional argentino entre los años 2006 y 2017, a partir de un relevamiento de datos propio. Dicho corpus se sustenta en las informaciones publicadas en sitios de Internet acerca de los incidentes ligados al fútbol reflejados en los principales periódicos nacionales, así como en el archivo de la ONG Salvemos al Fútbol. El objetivo consiste en presentar un mapa de las formas en las que ha manifestado la "violencia en el fútbol" en la última década, y comentar, en paralelo, las respuestas de políticas públicas de seguridad deportiva que han intentado reaccionar frente a hechos trágicos.

Palabras clave: Fútbol, Violencia, Políticas públicas, Seguridad pública, Argentina. 


\title{
TOWARDS A MAP OF "VIOLENCE IN FOOTBALL": ACTORS, DYNAMICS, PUBLIC RESPONSE AND CHALLENGES IN THE CASE OF ARGENTINA
}

\begin{abstract}
This paper analyzes a corpus of "episodes of violence" in Argentine professional football between 2006 and 2017, using data gathered by the author. It is based on information posted on Internet sites about incidents related to football and reported in the main national newspapers as well as in the archives of the NGO Salvemos al Fútbol. The objective is to compile a map of the ways in which "violence in football" has been expressed over the past decade and, at the same time, to comment the response of public policies on safety in sports, which have sought to react to tragic events.
\end{abstract}

Keywords: Football, Violence, Public policies, Public safety, Argentina. 


\section{INTRODUCCION}

Los episodios de violencia en el fútbol presentan una serie de desafíos de interpretación, pues estos no se tratan únicamente de violencia de y entre los aficionados, sino que involucran a una serie actores, situaciones y condiciones diversas que juegan sus papeles. Asimismo, las interpretaciones mediáticas, e inclusive aquellas de las ciencias sociales, difieren ampliamente en los análisis del fenómeno (Dunning 2000).

En este sentido, inspirados en las descripciones que Eduardo Archetti y Amílcar Romero (1994) propusieron para interpretar las muertes y los incidentes entre las décadas de 1950 y 1980 en Argentina, nuestro análisis, basado en las reflexiones más amplias presentes en las investigaciones producidas en los últimos 20 años, busca ofrecer nuevas herramientas sobre los hechos que la prensa registró como violencia relacionada con el fútbol entre 2006 y 2017. La idea que subyace en los medios de comunicación y en la mayoría de los dispositivos de políticas públicas previstos para hacer frente al problema, es aquella de "proteger a la sociedad" (Foucault 2000), es decir, protegerla de sus "malos elementos". En otras palabras, esto se traducen en Argentina en la figura de las "barras bravas", al igual que lo eran los hooligans en Inglaterra entre las décadas de 1960 y 1990.

Qué son las "barras bravas" y quiénes las integran son preguntas que no han tenido en Argentina un proceso definicional surgido desde la legislación ni desde las políticas públicas. Ese vacío de caracterización del "sujeto peligroso" ha sido llenado por los discursos de la prensa, siempre parciales y estigmatizantes. Desde la academia se ha insistido en definir a las "barras bravas" (Alabarces 2004, Sodo 2013, Murzi 2011), que en un primer momento caracterizaremos aquí como grupos que a través del uso real como simbólico del fervor y la capacidad de violencia, encabezan las actividades del colectivo de hinchas (aficionados activos) de su club y a su vez mantienen relaciones inestables de tipo social, económico y político con actores tanto del mundo del fútbol como de espacios extrafutbolísticos. Pero, ¿en qué medida son las "barras bravas" culpables de todas la(s) violencia(s) que ocurren en el fútbol argentino?

A partir de una mirada estadística intentaremos en este artículo discernir las dinámicas que los mass media, o grandes medios de comunicación en Argentina ${ }^{1}$, presentan como hechos de violencia en el fútbol. Esto, para construir descripciones que puedan ser contrastadas con las hipótesis de conflicto que circulan, las cuales tienden a ser reflejadas en las voces de

1 Cuya visión es en general reproducida por otros menores. 
funcionarios estatales y en políticas públicas (Segura et al. 2018). Como fue planteado en un artículo anterior (Segura y Murzi 2015), el problema de la violencia en el fútbol, definido con mayor o menor precisión, representa de cualquier forma un desafío para la gestión pública. Así, partiendo de un panorama histórico de perfiles y paradigmas de seguridad legislados (Sustas 2013) veremos cómo las expresiones de violencia han ido mutando, pero no tanto así las orientaciones de políticas públicas (Lasswell 1951).

Cabe distinguir, antes de entrar en los detalles, que existen formas de violencias visibles, que aparecen y se comentan en los grandes medios de comunicación, y otras invisibles a sus relatos. Dentro de esta última categoría entra todo aquello, que aunque en algunos casos se comenta con otros rótulos, no se considera como violencia en el tratamiento mediático. Por ejemplo, los escándalos de lavado de dinero y tráfico de influencias y sobornos, en particular en la zona CONMEBOL, no se contabilizan como hechos de violencia contra el fútbol, sino como escándalos de corrupción, que "solamente" involucran a una serie de individuos deshonestos, pero nunca a los tejidos protectores y a sus socios (porque precisamente son socios de los grupos donde la mayoría de los comentaristas trabaja). Mucho menos se considera como violencia cuando un periodista increpa o desafía a otros comentaristas en un panel de televisión, acusándolos de no tener "huevos" (coraje) para dar informaciones. Esas expresiones y formas de violencias, naturalizadas y por ende invisibilizadas, no ingresan en la narrativa noticiable como pertenecientes al universo de la "violencia en el fútbol”, con lo cual quedan fuera del análisis. Así, en este texto revisaremos aquello que se ha registrado como violencia física y ataques a la integridad física en el fútbol argentino, pero apuntamos a dejar ciertos interrogantes en las definiciones que permitan pensar, de diferentes maneras, el problema en torno a estas cuestiones.

\section{LA “VIOLENCIA”, LAS LEYES Y LAS MUERTES EN EL FÚTBOL ARGENTINO}

La "violencia” en el fútbol no es un invento contemporáneo en Argentina, sino que ha estado presente en diferentes manifestaciones desde los inicios de la práctica de este deporte (Duke y Crolley 2001, Frydemberg 2012). Para Archetti (1999) el fenómeno del fútbol se ha configurado históricamente en Argentina entre elementos festivos y trágicos, dando lugar a un tipo especial de ritual que oscila entre lo carnavalesco y lo violento. Los golpes, piedrazos, heridos y muertos han sido solamente una contraparte de ciertos cánticos, saltos rítmicos, banderas y performances sofisticadas de aliento. El trabajo del sociólogo Amílcar Romero (1985, 1986, 1994), pionero en el análisis de las tramas de la violencia en el mundo del fútbol, centró 
sus investigaciones en el período comprendido entre 1958 y 1983. Así, sus descripciones excedieron las interpretaciones iniciales que la literatura europea movilizaba para explicar el fenómeno del hooliganismo, vinculadas preponderantemente a las peleas entre aficionados de distintos equipos, como una prolongación del enfrentamiento simbólico en el campo de juego (Hall 1978, Dunning, Murphy y Williams 1986, Ingham 1978, Marsh 1978). El enfoque de Romero, tanto en sus trabajos en solitario como en los que produjo con Eduardo Archetti (1999), extendió el análisis hacia explicaciones que desbordaron el campo deportivo y lo ligaron a procesos sociales más amplios, como la represión policial, el funcionamiento de la ley, los negocios ilegales de los directivos de los clubes, los vericuetos de los procesos judiciales y el papel del poder institucional (Archetti y Romero 1994: 39).

La importancia de los trabajos de Romero para los estudios sociales sobre el fútbol producidos en Argentina tiene que ver con el ordenamiento de una serie de datos hasta allí inconexos, o débilmente vinculados. Romero prestó su principal atención a un tipo en particular: las muertes. Las víctimas funcionaron en sus investigaciones como un indicador capaz de hilvanar hipótesis y explicaciones a través de los años. La "etapa moderna" de la violencia en el fútbol de Argentina se inició, para Romero (Archetti y Romero 1994: 16) durante la segunda parte de la década de 1950, con cuatro perfiles determinados de muertes. El primero en ser identificado fue la represión policial. El segundo, las reacciones provenientes de grupos organizados contra aficionados de equipos rivales. Un tercero, materializado en dictadura, por la persecución política, como cuando la policía disparó sobre un grupo de aficionados de Huracán considerados extremistas de izquierda y mató a uno de ellos en el estadio de Estudiantes de La Plata en 1976. Y el cuarto, los ataques planificados de grupos sobre otros grupos organizados de hinchadas rivales, a la manera de una guerra de guerrillas. Estas últimas formas comenzaron a incluir, desde los años 1970, cierta sistematización, logística e incluso coordinación con funcionarios estatales para liberar zonas y tener protección antes o después de las "maniobras".

A partir del regreso democrático al país, en 1983, la violencia en el fútbol comenzó a ser percibida como un problema público. Esto se debió a tres motivos principales: 1) ciertos cambios operado en los grupos de hinchas organizados, donde la violencia fue adquiriendo preponderancia con la consolidación de las figuras de las "barras bravas" y su creciente asociación con el crimen y el delito; 2) la emergencia de los "pánicos morales" (Cohen 1972) por la caracterización de los medios de comunicación acerca de estos aficionados de fútbol; y 3) los cambios sociales y políticos que motivaron nuevas conflictividades en el proceso de restitución democrática (Kessler 
2008). El año 1985 fue central para la seguridad deportiva en Argentina debido a la sanción de la primera Ley Federal de regulación de la violencia en los espectáculos. La Ley 23.184, motivada por el crimen del joven Adrián Scasserra en el estadio de Independiente de Avellaneda, inauguró muchos de los supuestos sobre los cuales se irían desplegando las políticas de seguridad en las décadas subsiguientes. Esta ley preveía castigos penales para delitos realizados en el ámbito del espectáculo ${ }^{2}$ y sancionaba algunas prácticas concretas (porte de armas, formación de grupos, alteración de transportes urbanos). Pero, además, movilizaba numerosos sentidos sobre lo conflictivo y lo peligroso. Allí aparecen las primeras hipótesis de conflicto movilizadas por el Estado para explicar el fenómeno: el fanatismo entendido como pérdida de la racionalidad, la rivalidad deportiva y el desorden público en el espacio del estadio. También aparece el recorte espacio-temporal sobre el cual el Estado despliega sus dispositivos, tanto policiales como jurídicos, que en esta primera caracterización quedó restringido al estadio y a los momentos inmediatamente previos y posteriores al partido.

Si bien muchas partes de esta ley estaban pensadas en función del actor de riesgo que personifican las "barras bravas", en ningún pasaje de la misma figura una definición de lo que se entiende por "barras bravas". Al ser escamoteada la definición, la interpretación de la ley permitía reproducir, por lo tanto, los sentidos construidos por los medios de comunicación y ayudaba a legitimar el enfoque policial dominante, cuyos ejes eran la estigmatización, la simplificación y la criminalización. Esta ausencia de definición del sujeto a ser controlado sería una de las especificidades normativas del campo de la seguridad deportiva en Argentina hasta bien entrada la década de 2010. La otra especificidad normativa tendría que ver con el carácter de acting out (Garland 2005) de las políticas, ideadas siempre como respuestas reactivas del Estado inmediatamente luego de hechos de violencia que agitasen a la opinión pública.

Ahora bien, es pertinente notar que entre 1984 y junio de 2017 murieron en Argentina 210 personas por episodios vinculados con el fútbol. Si en los 62 años que pasaron desde el registro de las primeras víctimas en el fútbol (1922) hasta el fin de la dictadura (1983) murieron 2 personas por año en promedio, desde 1984 hasta 2017 esta ratio se elevó a más de 6 fatalidades

2 Algo novedoso respecto a las legislaciones europeas en la materia de esa época, que constituían los modelos de los cuales los funcionarios públicos locales tomaban las ideas para pensar las políticas públicas. Amílcar Romero (1994) afirma que Fernando De la Rúa tomó la gran parte del texto que luego se convirtió en la Ley 23.194, no preveía castigos penales especiales para delitos deportivos, por fuera de los que consignaba el Código Penal. 
por año. La trama de un gran número de las muertes entre los años 1980 y la década del 2000 (Murzi, Sustas y Uliana 2011) podía interpretarse a partir de una lógica vinculada, en el mundo de las hinchadas argentinas, a la noción de "aguante". El "aguante", en este contexto, se convirtió durante décadas en un concepto multiforme de significados y prácticas. Un capital simbólico (Garriga 2006) de jerarquías en el entramado de las hinchadas. A través de él se han disputado y reproducido identidades masculinas de agresividad (Aragón 2007, Alabarces 2004, Cabrera 2013, Czesli 2013, Gil 2007, Moreira 2005). Entre los ejemplos más representativos, están quizás, las muertes de Ángel Delgado y Walter Vallejos, dos aficionados de River Plate asesinados por la "barra brava" de Boca Juniors en una emboscada a la salida de la Bombonera en 1994. Más allá de que el hecho terminó con la cúpula de la "barra" de Boca Juniors en prisión, la hinchada luego reivindicó en sus cánticos esas muertes, asociándolas a la competencia simbólica con su clásico rival respecto a la posesión de "aguante".

No obstante, el perfil de las "barras bravas" y sus formas de actuar han mutado y evolucionado en las últimas décadas (Bergés 2015, D’Angelo 2012, Duke y Crolley 2001, Moreira 2012, Sain y Rodríguez 2014). Lo que puede verificarse es un doble desplazamiento de la violencia. En primer lugar, porque el recurso a la agresión física y el ataque (muchas veces con armas) ya no es empleado exclusivamente para competir contra hinchadas rivales, sino, sobre todo, contra los propios compañeros de pasión que integran facciones aspirantes al poder de la tribuna. Así, se han multiplicado los antagonismos internos. Y, en segundo término, porque los conflictos clásicos han dado paso a lo que podríamos llamar una cierta "privatización de la violencia" (Cabrera 2015); esto significa que las peleas ya no ocurren siempre en los estadios e inmediaciones, con los partidos de fútbol como principal escenario, sino que pueden ocurrir en otros momentos y lugares. En términos del indicador de muertes, este pasó a un promedio anual de nueve episodios en los últimos diez años (Segura et al. 2018).

Sin embargo, ante la heterogeneidad en la que se han manifestado algunas expresiones violentas, una pregunta se impone: ¿es suficiente con la observación de las muertes como principal indicador para dar cuenta de la amplitud del problema? ¿O es necesario extender la mirada hacia los episodios que no terminan con víctimas, pero que son más numerosos y por lo tanto frecuentes? Si bien un episodio de violencia "menor", puede poseer menos impacto mediático y no repercutir en diagnósticos de política pública, lo cierto es que los episodios de muerte constituyen, finalmente, las excepciones y no la constante cada semana. Las muertes son sucesos del orden de lo extraordinario. Pero, tomadas en perspectiva y comparadas con la de otros eventos masivos, o con el número en otros países, la cifra es, en 
efecto, elevada (Segura et al. 2018).

Los muertos del fútbol son visibles y han funcionado como indicador para inferir conclusiones generales a partir de hechos particulares (Archetti y Romero 1994, Murzi, Sustas y Uliana 2011). En este sentido, los medios de comunicación han enfatizado desde la década de 1980 a las "barras bravas" como el núcleo del problema, interpretación, que como ya vimos, ha sido recogida por los textos legales (Sustas 2013) y las políticas de seguridad deportiva. Empero, las ciencias sociales han desafiado esta mirada, sugiriendo una percepción más amplia, la cual señala el hecho que todos los actores del mundo del fútbol recurren a prácticas violentas de una $\mathrm{u}$ otra forma (Garriga 2013). Alrededor de los partidos de fútbol se despliega un repertorio de prácticas, de distinta índole y tenor, llevadas a cabo por una multiplicidad de individuos, que configuran ambientes de violencia: "un envolvente clima de tensión, mortificación, hostilidad y dramatismo que predomina por sobre el componente festivo y carnavalesco del ritual futbolero" (Sodo 2013: 22). Esas prácticas pueden incluir amenazas reales a jugadores por parte de los aficionados, peleas a golpes dentro del campo de juego, cánticos racistas y homofóbicos, y maltrato policial (Taddei 2016) hacia los espectadores, entre varias otras manifestaciones.

Es en esta dirección que nuestra contribución se centra, específicamente, entre los años 2006 y 2017, para discernir los actores que aparecen en escena, los lugares y la naturaleza de los incidentes. ¿En qué porcentaje están involucradas las "barras" sobre el total de hechos de violencia registrados? La propuesta que se desarrolla tiene por objetivo ampliar la mirada de hechos que no se limiten únicamente a los fallecidos, sino a todo un repertorio de prácticas. Esta empresa tiene varios motivos, así como obstáculos que serán detallados en el siguiente apartado, pero un comentario acerca de la disponibilidad de información se impone en primer lugar. Dos meses luego de asumir una nueva gestión de gobierno en el Estado (Mauricio Macri), en febrero de 2016, la Dirección Nacional de Seguridad en Espectáculos Futbolísticos (DNSEF), organismo dependiente del Ministerio de Seguridad de la Nación solicitó a la Organización No Gubernamental (ONG) Salvemos al Fútbol'3 ${ }^{3}$ de la cual uno de los autores es vicepresidente, datos sobre incidentes relacionados a la violencia en el fútbol. De este pedido, pudimos inferir que no existía información sistemática producida por el Estado a este respecto, o al menos que no estaba disponible. Finalmente, el intercambio nunca se produjo, pero dio la pauta acerca de la necesidad de avanzar en la producción de insumos para la gestión y las políticas públicas.

3 http://salvemosalfutbol.org/lista-de-victimas-de-incidentes-de-violencia-en-el-futbol/ 
De este modo, se presenta aquí una contribución, incipiente, sobre las cifras de episodios identificados desde 2006, año en que se creó la ONG Salvemos al Fútbol (Murzi y Segura 2014) y el año 2017. La pregunta que guió la elaboración de este registro fue: ¿cuáles han sido las formas que la violencia alrededor del fútbol ha tomado en la última década? En torno a esa idea central, orbitan una serie de hipótesis que serán puestas en cuestión:

- Entre 2006 y 2017 hubo un aumento de las peleas internas en las hinchadas en detrimento de las peleas entre aficionados tradicionalmente rivales.

- $\quad$ Las políticas públicas de prohibición del público visitante (aplicadas desde 2007 para los torneos de Ascenso y en 2013 ampliado también al torneo de Primera División) han contribuido a exacerbar los conflictos internos.

- Contrariamente a décadas anteriores, cuando los hechos de violencia ocurrían dentro o en las inmediaciones de los estadios, ha habido un número creciente de episodios lejos de los estadios.

- Los conflictos producto de instancias deportivas (descensos, definiciones de torneos, arbitrajes perjudiciales, etc.) que ponen en juego sentidos vinculados al deporte (honor, identidades, justicia, etc.), continúan siendo numerosos y frecuentes.

- $\quad$ El desarrollo de medios (sitios web, redes sociales) y dispositivos tecnológicos (smartphones) ha contribuido a magnificar el alcance de la "violencia en el fútbol", en la medida en que pone en conocimiento incidentes que en décadas anteriores no hubiesen llegado al gran público, ya sea por ocurrir en partidos de poca importancia o en espacios sin cobertura mediática tradicional.

- La participación de otros actores, que no están vinculados con las "barras bravas" quedan minimizados en los medios de comunicación frente al discurso extendido que asocia "barras" y violencia en una operación metonímica.

\section{ASPECTOS METODOLÓGICOS: ENTRE DEFINICIONES, FUENTES Y VARIABLES DE ANÁLISIS}

La primera decisión metodológica que debimos enfrentar fue la de definir aquello que podíamos considerar como un "hecho o episodio de violencia en el fútbol". A diferencia de las muertes, que son indiscutibles, un "hecho de violencia" necesita ser definido a priori, en la medida en que la violencia es un concepto polisémico y multidimensional. Para ello, nos apoyamos en la caracterización que hace Georges Vigarello (2000) respecto a las violencias que tienen lugar en el mundo del deporte: la violencia simbólica, 
la violencia indirecta, la violencia directa de los protagonistas y la violencia directa de los espectadores (2001: 6). Sobre la violencia simbólica, Vigarello recupera los postulados de Bourdieu y Passeron (2001) para señalar que se trata de una violencia que no se manifiesta físicamente pero que tiene como víctimas a las "minorías de todos los órdenes: generacionales, sociales, culturales" (2001: 7), a quienes se impone un modelo dominante fuertemente jerarquizado y desigual. En cuanto a la violencia indirecta, sostiene que es la provocada "no por la voluntad de los actores sino por las consecuencias inesperadas de sus acciones, su contexto y el entorno" (2001: 7). Respecto a la violencia directa, tanto hacia los protagonistas como hacia los espectadores, la definición de Vigarello corresponde a: "agresiones físicas cometidas intencionalmente y por la fuerza contra una persona" (2001: 8). Nos centramos aquí, con las limitaciones ya señaladas, sobre estas últimas dos dimensiones que propone Vigarello -la violencia directa contra los protagonistas y espectadores- para delimitar los hechos que forman parte de nuestro relevamiento. Necesitamos, empero, dejar en claro que nuestra concepción de "violencia" excede el mero espectro de las agresiones físicas. Compartimos la caracterización del sociólogo noruego Johan Gatlung (1969) respecto que la violencia física y directa es solo una parte de los conflictos sociales, una consecuencia de dos tipos de violencia más amplios, la cultural y la estructural.

Sin embargo, para nuestro relevamiento, solo tomamos en cuenta los hechos que involucran violencia física, debido a tres motivos. En primer lugar, porque son plausibles de clasificación; en segundo lugar, porque son los que se convierten habitualmente en noticia y, como nuestro relevamiento fue hecho sobre medios de prensa, son el tipo de hecho al que hemos tenido acceso. Y, en tercer lugar, porque la violencia directa es en definitiva la que determina y habilita las políticas públicas de seguridad deportiva. Así, los hechos que relevamos incluyen: peleas entre aficionados, represión policial, agresiones a jugadores, árbitros, dirigentes $\mathrm{y}$ entrenadores, peleas entre protagonistas (jugadores, entrenadores, árbitros) y destrozos o dańos contra bienes materiales ligados a los clubes o estadios (incendio de instalaciones, piedrazos arrojados al campo de juego, sedes o estadios baleados, asalto o destrozo de comercios aledaños, etc.). La única excepción hecha de incidentes que no involucra directamente violencia física, fue respecto a las amenazas verbales de muerte consumadas por medios privados y no por cánticos (algo que es bastante habitual en muchos de ellos). Se tratan de amenazas de aficionados ("barras" y no "barras") hacia jugadores, entrenadores o dirigentes. Decidimos incluirlas cuando involucran un amedrentamiento directo a través del uso de armas, o cuando coaccionan sobre bienes materiales de los amenazados (daños en automóviles, pintadas en los domicilios particulares), considerando que el 
avance sobre un bien físico constituye una agresión directa hacia la víctima.

Una vez determinada nuestra unidad de análisis, nos encontramos frente al problema de obtener los datos. Decidimos entonces trabajar con dos fuentes: las informaciones presentes en los principales medios de comunicación del país y el archivo de la ONG Salvemos al Fútbol. De Salvemos al Fútbol tomamos los casos de víctimas fatales y las informaciones sobre otros episodios violentos que en los once años de existencia de la asociación fueron recopilados. Para darle una sistematicidad a esos archivos, y a fin de definir un universo claro para la muestra, procedimos a una búsqueda sistemática en medios de prensa a través de Internet. Sobre cada mes de cada año en el período 2006-2017 realizamos una búsqueda avanzada para las palabras "violencia fútbol", "violencia en el fútbol" e "incidentes fútbol" tanto en el motor de búsqueda (seleccionando informaciones solo de sitios argentinos) como en los buscadores internos de los periódicos La Nación, Clarín y Olé, que son aquellos que tienen más lectores y un archivo considerable de noticias. Sobre esa búsqueda procedimos a leer, durante meses, cada resultado, para comprobar si efectivamente se trataba de un hecho cuyos criterios se ajustaban a los que definidos para incluirlo en la base. Luego se hizo otra búsqueda sobre más portales de alcance nacional: Tiempo Argentino, Página 12, Télam, Crónica, Minuto Uno, Infobae, para completar registros o detalles complementarios. Para obtener información sobre las divisiones menores se recurrió a la web especializada Solo Ascenso. Además, para reducir la sobrerrepresentación inevitable de fuentes sesgadas a la concentración económica y social en torno a Buenos Aires y alrededores (Gaffney 2009), se consultaron periódicos de otras ciudades y provincias: El Día, la Capital, Rosario Plus, La Gaceta, La Voz, y Jujuy al Día entre otros.

La principal debilidad en términos metodológicos que contiene esta base, radica en el hecho de que no pudo escapar de la concepción noticiable de los hechos, propia de la lógica de los medios de comunicación. Sin embargo, dos cuestiones fueron "aprovechadas" para nuestra tarea en este sentido. La violencia en el fútbol constituye en Argentina una mercancía para los medios (Szlifman 2010), al igual que ocurría en Gran Bretaña en la década de 1970 (Hall 1978); por lo cual, estos tienden a reflejar todo lo que consideren un acto de violencia relacionado a este deporte. Y la segunda, es que, a partir del avance de los medios electrónicos y los dispositivos digitales, se produjo una multiplicación de la información que ayudó a nuestro relevamiento, sobre todo en los detalles de hechos puntuales a partir del año 2014 en adelante. Para cada hecho tratamos de identificar, así, una serie de actores, atributos y características. Con estas consideraciones, fueron creadas las siguientes variables para clasificar 
información.

Tabla 1: Variables utilizadas para clasificar información

\begin{tabular}{|c|c|c|}
\hline Variable & Tipo & Categorías \\
\hline Mes & Temporal & $\begin{array}{l}\text { Enero, Febrero, Marzo s, Abril, Mayo, } \\
\text { Junio, Julio, Agosto, Septiembre, } \\
\text { Octubre, Noviembre, Diciembre }\end{array}$ \\
\hline Año & Temporal & Todos los años entre 2006 y 2017 \\
\hline $\begin{array}{l}\text { En el marco del } \\
\text { partido }\end{array}$ & $\begin{array}{l}\text { Espacio- } \\
\text { temporal }\end{array}$ & $\begin{array}{l}\text { Sí } \\
\text { No }\end{array}$ \\
\hline $\begin{array}{l}\text { En el marco del } \\
\text { partido (Sí) }\end{array}$ & $\begin{array}{l}\text { Espacio- } \\
\text { temporal }\end{array}$ & $\begin{array}{l}\text { Dentro del estadio } \\
\text { En las inmediaciones del estadio } \\
\text { Fuera de las inmediaciones }\end{array}$ \\
\hline $\begin{array}{l}\text { En el marco del } \\
\text { partido (No) }\end{array}$ & $\begin{array}{l}\text { Espacio- } \\
\text { temporal }\end{array}$ & $\begin{array}{l}\text { Motivaciones relacionadas al fútbol } \\
\text { Asuntos extrafutbolísticos }\end{array}$ \\
\hline Actores & $\begin{array}{c}\text { De } \\
\text { situación }\end{array}$ & $\begin{array}{l}\text { "Barra brava" identificada, Otro tipo de } \\
\text { aficionados, Policía, Jugadores/cuerpo } \\
\text { técnico, Dirigentes, Otros }\end{array}$ \\
\hline $\begin{array}{l}\text { Tipo de } \\
\text { incidente }\end{array}$ & $\begin{array}{c}\text { De } \\
\text { situación }\end{array}$ & $\begin{array}{l}\text { Peleas entre hinchas del mismo equipo, } \\
\text { Peleas entre hinchas de equipos rivales, } \\
\text { Represión policial, Agresiones de } \\
\text { hinchas a jugadores/cuerpo técnico, } \\
\text { Agresiones de hinchas a dirigentes, } \\
\text { Agresiones entre protagonistas, } \\
\text { Destrozos y daños, Agresiones a árbitros, } \\
\text { Accidentes (en caso de muerte) }\end{array}$ \\
\hline $\begin{array}{l}\text { Desenlace del } \\
\text { incidente }\end{array}$ & $\begin{array}{c}\text { De } \\
\text { situación }\end{array}$ & $\begin{array}{c}\text { Muertos, Heridos, Detenidos, Daños } \\
\text { materiales, Agresiones, Amenazas }\end{array}$ \\
\hline $\begin{array}{c}\text { Equipo(s) } \\
\text { involucrado(s) }\end{array}$ & Del juego & \\
\hline División & Del juego & $\begin{array}{c}\text { Primera A, Nacional B, Primera B } \\
\text { Metropolitana/Torneo Federal A, } \\
\text { Primera C/Torneo Federal C, Primera } \\
\text { D, Ligas Regionales, Amistoso, Copa } \\
\text { Argentina, Internacional, Fútbol sala } \\
\text { (Asociación del Fútbol Argentino, AFA), } \\
\text { Divisiones juveniles } \\
\text { Fuente: Elaboración propia }\end{array}$ \\
\hline
\end{tabular}




\section{MAPA DE LAS “VIOLENCIAS” EN EL FÚTBOL ARGENTINO 2006-2017}

En total fueron desglosados 623 incidentes en el relevamiento que comprende el periodo entre 2006 y $2017^{4}$. Esta población, en términos estadísticos, es la que podemos considerar como nuestra base de hechos de violencia ocurridos en el marco del fútbol argentino reflejados en algún medio de prensa. El gráfico a continuación muestra sus oscilaciones de forma anual.

\section{Gráfico 1: Evolución de número de hechos de violencia 2006-2017}

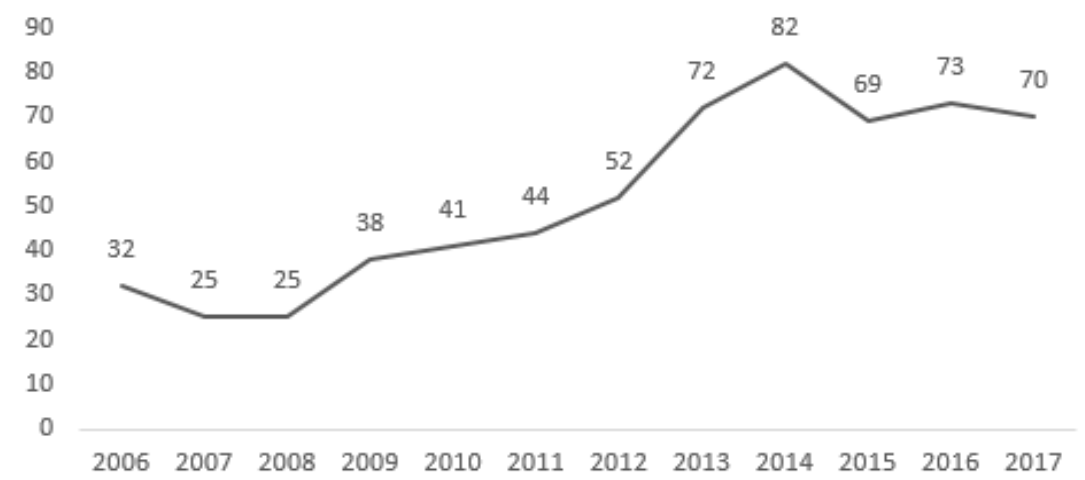

Fuente: Elaboración propia.

El gráfico confirma, de inicio, algo que señalamos respecto a la percepción que existe acerca de la violencia en el fútbol: al igual de lo que sucede con el delito en Argentina (Kessler 2008), se ha tendido a presentarla en los medios como un problema en constante crecimiento y sobre el cual las acciones de control y prevención no han funcionado para contenerlo. Pero, ¿quiénes están involucrados en los episodios registrados? Como anunciamos

4 Queremos dejar claro al lector que este número de 623 episodios se deriva de un resultado inicial del relevamiento, el cual consideró 651 casos (Segura et al. 2018). La diferencia es que, al revisar, el análisis de ciertos hechos, nos quedaron dudas sobre 28 casos y su clasificación inicial. De algunos, consideramos que estaban envueltos en episodios ya registrados y eran consecuencias directas, pero no era adecuado registrarlos como casos separados y otros, que no eran exactamente violencia del o en el fútbol, sino que eran episodios que involucraban a algún actor o miembro de una barra, pero en casos que nada tenían que ver con el fútbol. Ofrecemos así al lector una versión más calibrada aquí. Nuestra intención no es la de nutrir de la mayor cantidad de datos a nuestra base para mostrar mayor robustez estadística, sino presentar mejor calidad en la clasificación de la información. 
en la introducción, las "barras bravas" son consideradas por los discursos mediáticos, políticos y legislativos como el actor responsable, absoluto y dueño, de la violencia en el fútbol. Frente a esta acusación extendida que atribuye un monopolio, nos preguntamos: ¿quiénes son los otros actores que también despliegan prácticas violentas? Para discernir esto hagamos primero una distinción conceptual. En cada hecho puede haber más de un actor involucrado (por ejemplo, "barras", "otro tipo de hinchas", policía, jugadores, dirigentes), con lo cual, la participación es el número porcentual de aparición de cada actor sobre el total de participación de todos los actores. Al medir la "participación", a partir de nuestros datos, resulta que el $74 \%$ de los involucrados son aficionados (hinchas), y el restante 26\% son otros actores. Como señalamos en el apartado metodológico, nuestra decisión para medir esta variable implicó una distinción entre miembros identificados directamente con las "barras", y miembros no identificados con estos grupos. En ese esquema, obtuvimos un resultado "bruto" previsible, pero no tanto en su envergadura: el actor que aparece con más frecuencia en los hechos son en efecto las "barras bravas", con un 63\% aproximado en su participación.

Estos datos validan, en cierta forma, las visiones oficiales sobre su conflictividad, es decir, grupos problemáticos a partir de los cuales se estructuran las políticas públicas de seguridad. El restante de la "participación" se lo dividen la represión de la policía (14\%), incidentes producidos por otro tipo de aficionados (11\%), incidentes protagonizados por jugadores y cuerpo técnico (10\%) y otros actores -dirigentes, periodistas, seguridad privada (el $2 \%)$.

Así, si nos detenemos en ese $63 \%$ atribuido a las "barras", esto implica admitir que en más de la mitad de los casos estuvieron presentes, pero a su vez, revelar que en casi el $40 \%$ de los episodios no lo estuvieron. Si las políticas de seguridad se conciben entonces a partir del deseo de controlar a las "barras bravas", si las legislaciones se estructuran sobre la idea de que las "barras" son el actor violento por excelencia, ¿qué ocurre con ese $40 \%$ restante de los incidentes? Llama aquí la atención la alta participación del resto de los aficionados, a priori no sindicados de "violentos" por los discursos oficiales o mediáticos. Esto incluye también aquellos que asisten sentados a sus plateas y desde cuyos espacios son arrojadas muchas veces monedas, botellas y hasta asientos contra otros aficionados, jugadores o árbitros. El gráfico a continuación ayuda a ilustrar la naturaleza de los incidentes identificados. 
Gráfico 2: Tipo de incidente ocurrido, 2006-2017

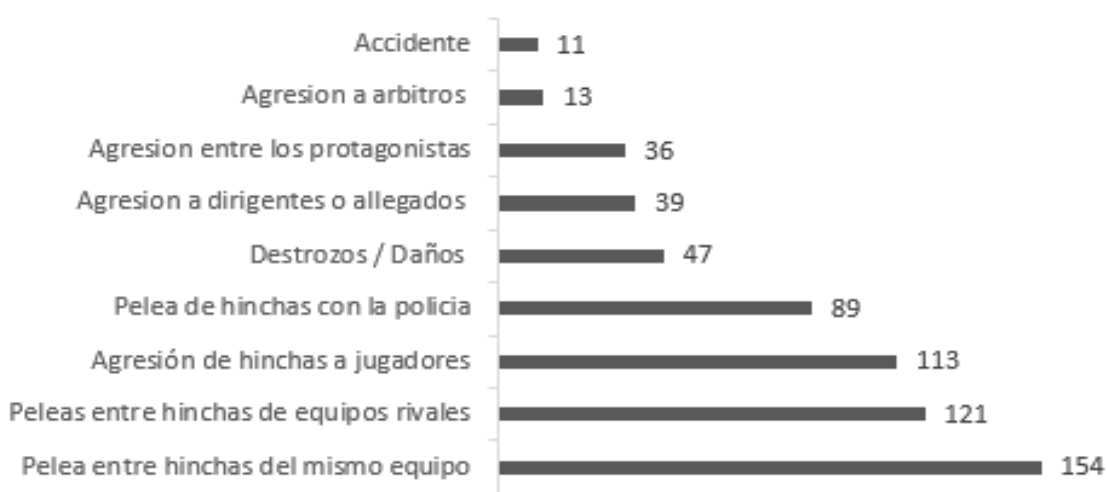

Fuente: Elaboración propia.

Veamos a continuación cómo podemos desglosar, y describir, algunos detalles de estos tipos de incidentes, agrupados por los principales hallazgos del gráfico anterior.

\section{CONFLICTOS INTRAHINCHADA}

Las peleas entre hinchas del mismo equipo motivaron el 24\% de los incidentes ocurridos en nuestro período de análisis, ubicándose como la principal causa de agresiones. Además, si tomamos solamente a los hechos que terminaron con víctimas fatales, la injerencia de las peleas entre hinchas del mismo equipo se duplica. Los datos confirman lo que varias investigaciones ya señalaban a partir de las muertes como indicadores (Murzi, Sustas y Uliana 2011, Cabrera 2015, Segura et al. 2018). Del total de muertes ocurridas en estos once años de análisis, el 56\% se debió a peleas internas en las hinchadas.

De acuerdo con los datos presentados en el gráfico a continuación, podemos sostener que la violencia intrahinchada se revela como más sangrienta y mortífera que el resto de las violencias. Es más probable que un hecho que involucre peleas internas acabe con un muerto, comparado con los demás tipos de incidentes. 
Gráfico 3: Muertes según tipo de incidente, 2006-2017

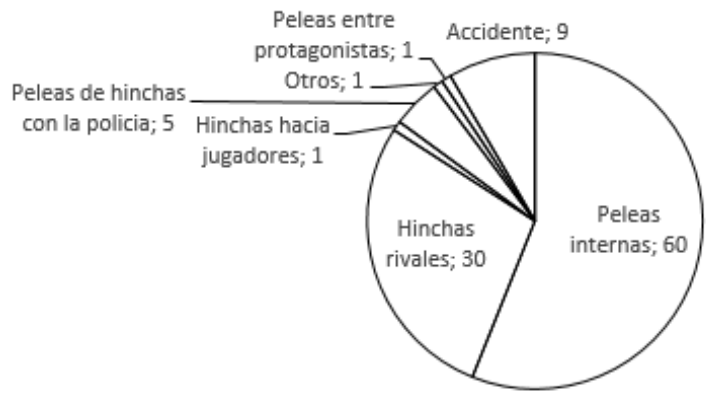

Fuente: Elaboración propia.

El caso de la "barra" de River Plate, denominada como Los Borrachos del Tablón, es ilustrativo de esta tendencia. En 2007, uno de sus miembros de alta jerarquía, Gonzalo Acro, fue asesinado por sus compañeros de tribuna, dando lugar a una investigación judicial que expuso, en los medios de comunicación, los mecanismos de funcionamiento de una de las "barras bravas" más importante del país. Como consecuencia, cinco "barrabravas" fueron condenados a cadena perpetua, entre ellos dos de sus líderes, los hermanos Schlenker, quienes han denunciado en múltiples entrevistas toda una trama de enredos, facciones pagadas por las dirigencia y conflictos entre partes. La historia de la "barra" de River Plate exigiría largas páginas para ser narrada y analizada (Carrozza 2015) y es en sí misma un objeto entero de investigación académica, debido a su complejidad. Aquí solo nos limitaremos a señalar que, a partir del registro de los hechos de violencia, y sobre aquellos ligados al núcleo duro de su hinchada, se puede observar de forma evidente la relación entre los incidentes y las disputas por espacios de poder.

La muerte de Acro funcionó como corolario de peleas internas de la "barra" que venían ocurriendo en espacios públicos, y a su vez, sirvió como punto de partida de nuevos enfrentamientos. En el mismo año de su muerte, un dirigente había sido acuchillado y se habían registrados dos grescas de grandes proporciones dentro del club (la "batalla de los Quinchos" y la "batalla del Playón"). En 2008, se registró una pelea entre facciones en el estadio de Vélez Sarsfield; en 2010 un miembro de un grupo de la "barra", Jonathan Wladmeier, fue asesinado. Ese mismo año, durante la misa en memoria de Acro, se produjo un enfrentamiento a tiros. Las disputas siguieron año tras año. En 2012, por ejemplo, fue asesinado el jefe de la facción disidente, La Banda del Oeste, aunque los motivos no han quedado claros. En noviembre del 2014, hubo otra pelea dentro 
de la confitería del club, un lunes por la tarde, que dejó un apuñalado e importantes daños materiales ${ }^{5}$. Si tomamos de nuestra base de datos, solamente los incidentes que involucran a River Plate, más la mitad de los 40 registros se deben a peleas intrahinchada. Muy atrás aparecen las peleas de hinchas de River Plate con aficionados rivales, y en menor medida otro tipo de agresiones. Como lo muestra el gráfico siguiente.

Gráfico 4: Tipo de incidente en los que River Plate se vio involucrado, 2006-2017

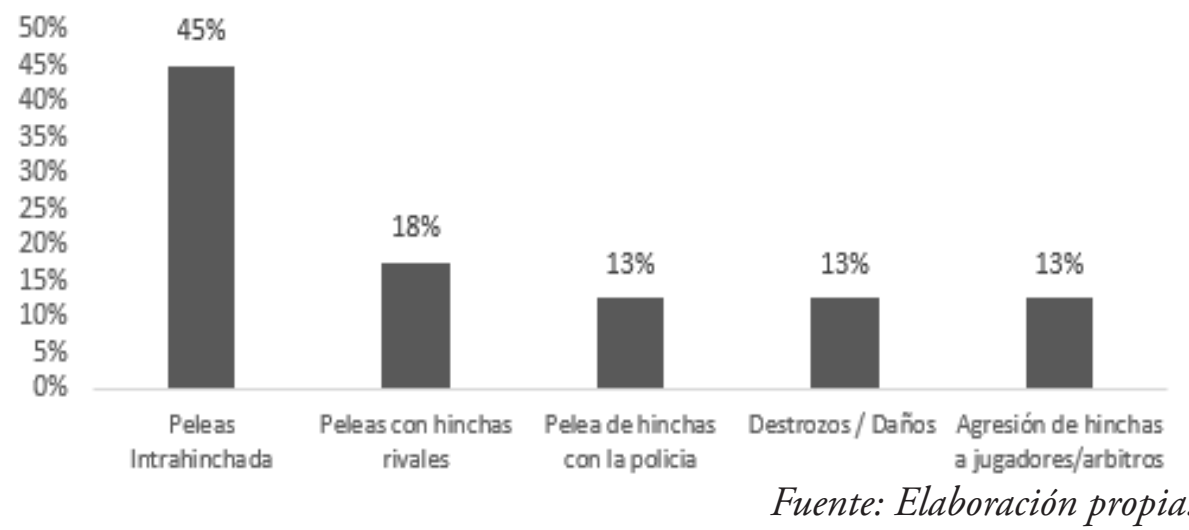

Frente a las disputas entre grupos de las hinchadas por el control de las tribunas, las respuestas de los clubes, y de las fuerzas del orden han tendido a reconocer a la facción capaz de imponer su liderazgo, ya sea a través de la victoria sobre sus competidores o por medio de negociaciones y acuerdos (Garriga et al. 2017, Segura et al. 2018). El acceso al estadio para el grupo ganador -reconocido como "barra oficial" en el lenguaje de la seguridad deportiva- ha reducido a otros grupos - "barra disidente" - a un doble estado de marginalidad. Esta situación ha sido detonante de las disputas para preservar, o intentar conquistar espacio.

Esta dinámica no se limita lógicamente a River Plate, sino que es extensiva a la mayor parte de las "barras bravas" argentinas. En el relevamiento encontramos episodios de este tipo en la mayoría de los clubes. En la última década, hubo muertos por peleas intrahinchada en River Plate, Boca Juniors, San Lorenzo, Racing, Independiente, Vélez Sarsfield, Huracán, Estudiantes de La Plata, Rosario Central, Newell's Old Boys, Colón de Santa Fe, Unión de Santa Fe, Lanús, Banfield, Chacarita Juniors, Defensa

5 El jefe de seguridad de River Plate en ese entonces Eugenio Burzaco, quien abandonaría su cargo en el club poco tiempo después del incidente y con el tiempo asumiría en el gobierno de Cambiemos como Secretario de Seguridad de la Nación. 
y Justicia, Almirante Brown, Nueva Chicago, Gimnasia y Esgrima de La Plata, Tigre, Belgrano de Córdoba, San Martín de Tucumán, Gimnasia y Esgrima de Jujuy, San Martín de San Juan y varios otros equipos de campeonatos del Ascenso y de torneos federales del interior del país. Al analizar en detalle los casos de incidentes intrahinchada, podemos sugerir una diferenciación en dos grandes ejes: 1) aquellos ligados a las disputas por el liderazgo de la hinchada, por cuestiones de política interna del club, por los negocios anclados al espectáculo futbolístico; y 2) aquellos vinculados a otros mundos sociales, mayoritariamente a las actividades económicas informales y delictivas.

La diferencia que proponemos respecto del origen de los incidentes es sutil y en ocasiones difícil de establecer con claridad. Incluso, muchas veces ambas motivaciones se entremezclan, en tanto la realidad social se rehúsa a cernirse a las categorías que las ciencias sociales intentan imponerle. Pero, el esfuerzo en la distinción tiene por fin generar una aseveración: en ocasiones, conflictos de índole extrafutbolística encuentran en la tribuna un escenario para su resolución, cargándose inevitablemente en la cuenta de la violencia en el fútbol. Esto es una consecuencia de la diversificación de los perfiles de los miembros de las hinchadas (Murzi 2011), un proceso que, aunque pueda parecer ajeno al futbol está íntimamente ligado a la configuración específica de las hinchadas argentinas y a los nexos que los miembros de las "barras" establecen con actores de poder en diversos ámbitos, a partir de la visibilidad que les da su pertenencia a la tribuna. Ahora bien, veamos la naturaleza de la vigencia de los enfrentamientos entre aficionados rivales, los cuales a pesar de haber disminuido en relación a esta tendencia intrahinchada, todavía representan un aproximado de $20 \%$ del total de incidentes identificados entre 2006 y 2017 y un $30 \%$ de las muertes según el gráfico mostrado.

\section{ENFRENTAMIENTOS “CLASICOS” ENTRE HINCHAS RIVALES}

En segundo lugar, entre los tipos de incidente se hallan las peleas entre aficionados rivales, dinámica que en décadas pasadas en Argentina, y en otros países (Hollanda 2017, Carrión 2014, Castro 2013, Segura 2013, Tsoukala 2009) representa el problema principal asociado a la violencia en el fútbol. Si tuviésemos que señalar un caso paradigmático en el abanico de nuestro relevamiento, sería sin dudas la muerte del aficionado del club Tigre, Marcelo Cejas en 2007, en el barrio de Mataderos. En un partido capital, donde se disputaba el ascenso de Tigre a la Primera División o el descenso de Nueva Chicago a la segunda, los hinchas de Chicago invadieron el campo de juego a minutos del final del encuentro que su equipo perdía. Con el descenso consumado, se desató una batalla que tuvo lugar en varios 
escenarios: el campo de juego (donde atacaron a jugadores), las tribunas (donde se enfrentaron ambas parcialidades) y las inmediaciones del estadio (donde hubo vehículos incendiados, enfrentamientos con la policía y gases lacrimógenos). A metros del estadio, Marcelo Cejas recibió el impacto de una piedra en el rostro y quedó tendido en la calle. Allí fue alcanzado por los pares de Nueva Chicago, quienes lo golpearon hasta que falleció.

La muerte de Cejas fue el episodio que motivó la prohibición del público visitante, una medida que marcaría al fútbol argentino en la década subsiguiente. A partir de ese momento, la interdicción de concurrencia de parcialidad visitante quedó establecida para todas las categorías de Ascenso. A partir del año 2013, se ampliaría a la Primera División, tras otro hecho trágico que involucró la muerte de Marín Jerez, producto de la represión policial en las afueras del estadio de la ciudad de La Plata.

La prohibición del visitante incidió en desactivar escenarios entre hinchadas rivales. En dos de los primeros tres años de nuestro relevamiento, la confrontación entre hinchas de distinta camiseta era el tipo de incidente más usual. Pero a partir del 2009 y hasta la actualidad, solo en 2011 esta dinámica volvió a ser la más repetida. En el Gráfico 5 se observa cómo la participación de las peleas entre hinchas rivales fue bajando respecto al total de incidentes ocurridos cada año.

Gráfico 5: Peleas entre hinchas rivales. Porcentaje sobre el total de incidentes de cada año, 2006-2017

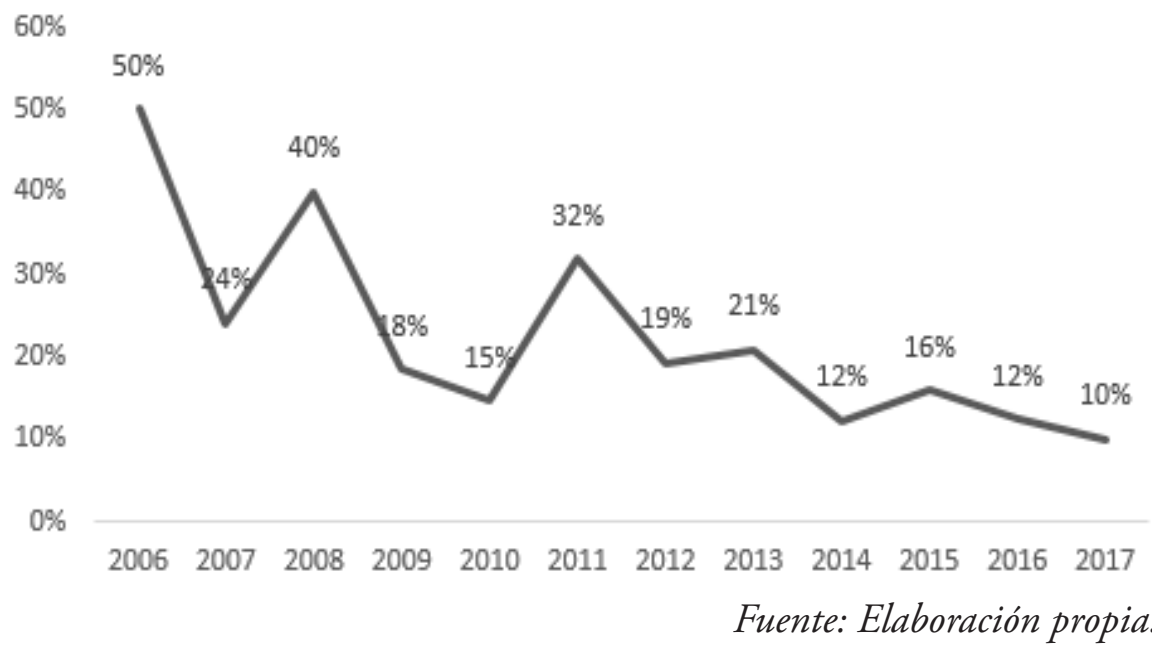

Un escenario nítido que aparece al observar esta categoría, es que muchos de los episodios involucraron a equipos con rivalidades fuertes, ya sea históricas, o territoriales. Se registraron repetidamente peleas en 
los derbis provinciales de Tucumán, Sala, Mendoza, Córdoba y Santa Fe entre los años 2006 y 2013. También incidentes periódicos entre equipos con rivalidades provinciales. En la ciudad de Buenos Aires y el conurbano bonaerense, asiento de la gran mayoría de los equipos que participan en los torneos principales de AFA, las rivalidades también están vinculadas a incidentes. La identificación del club con el barrio tradujo el enfrentamiento futbolístico en términos espaciales. Testigo de ello fue la muerte de Rodrigo "Cafú" Silvera en 2008 tras un enfrentamiento entre las "barras" de San Lorenzo y de Huracán. Ambas escuadras comparten calles, plazas y espacios barriales en una zona del sur de la Ciudad de Buenos Aires. Otros casos que se inscriben en esta lógica fueron la muerte del aficionado de Vélez Sarsfield, Emanuel Álvarez, asesinado en 2008 por un disparo de arma contra el autobus que transportaba a la parcialidad hacia el estadio de club de Boedo, así como el enfrentamiento a tiros entre hinchas organizados de Gimnasia y Esgrima y Estudiantes por las calles de La Plata en 2013.

La confrontación deportiva que durante diez años generó mayores hechos de violencia fue de los dos equipos principales de Rosario, Newell's Old Boys y Rosario Central. Más de diez incidentes fueron registrados en nuestra base. Damos por sentado que varios más que pueden haber sido omitidos por la prensa. Entre los hechos relevados se hallan asesinatos, grescas, amenazas, casas baleadas y propiedades incendiadas, entre otras expresiones violentas. El hecho más sangriento de la década tuvo lugar en diciembre de 2013, cuando el conductor de una camioneta donde un grupo de simpatizantes de Newell's Old Boys abandonaban el estadio, discutió con dos personas en una motocicleta, una de las cuales llevaba una camiseta de Rosario Central (por miembros aparentemente no ligados a la "barra"). La camioneta fue atacada a tiros a pocas cuadras de distancia. Dos individuos que viajaban dentro, Leonardo Boladian y Walter Palacios fueron asesinados, mientras que una mujer y su hija de siete años resultaron gravemente heridas. Estos enfrentamientos ponen en juego sentidos ligados a las interpretaciones atravesadas por la categoría de "aguante" (Aragón 2007, Garriga 2006).

A veces, esas lógicas de honor imaginado y reputación, tanto de las hinchadas como de los equipos de los cuales los aficionados esperan un mejor desempeño, producen también un número importante de agresiones hacia los protagonistas del juego. 


\section{AGRESIONES CONTRA PROTAGONISTAS DEL JUEGO}

En el tercer lugar de las categorías más repetidas en la variable "tipo de incidente" en nuestra base, aparece las agresiones hacia jugadores y entrenadores. Las modalidades de este tipo de violencia son diversas, pero repetidas. Veamos algunos ejemplos para graficarlas. En mayo de 2009 alrededor de 30 miembros de la "barra" de Deportivo Morón ingresaron al vestuario de su equipo portando armas blancas y golpearon a los jugadores, amenazándolos con matarlos si no clasificaban a la siguiente fase del torneo. En octubre de 2010 fue arrojada una piedra desde la tribuna de Independiente que impactó en la cabeza del arquero de Defensor Sporting de Uruguay, Martin Silva. En abril de 2013, "barras" de Deportivo Español ingresaron al vestuario visitante y golpearon a los jugadores de Berazategui. En febrero de ese mismo ańo, el microbus que trasladaba a los jugadores de Excursionistas fue baleado en las inmediaciones del estadio de El Porvenir. En septiembre de 2014, el arquero de Boca Juniors, Agustín Orión recibió el impacto de un proyectil arrojado desde la tribuna de Rosario Central. En el año 2015 un jugador de Lanús, Matías Fritzler, fue atacado con un golpe de puño por parte de un aficionado, sin relación alguna con la "barra", cuando daba una entrevista luego de una derrota. En mayo de ese año, un aficionado de Boca Juniors arrojó gas pimienta a los jugadores de River Plate cuando estos salían a disputar el partido, provocando un escándalo de dimensiones internacionales que terminó con la descalificación del equipo de la Copa Libertadores. En marzo de 2017, la "barra" de Gimnasia y Esgrima de Jujuy golpeó, robó y amenazó a sus propios jugadores.

Frente a un escenario de malas campañas o falta de éxitos futbolísticos esperados, aparece la "barra", o aficionados no vinculados a estos grupos también, para exigir respuestas. Esas apariciones (conocidas en el lenguaje futbolero bajo el eufemismo de "visitas" en el caso de las "barras") cobran notoriedad cuando "pasan a mayores", con agresiones físicas, destrozos, o intimidación con armas hacia los amenazados. El argumento que legitima esas amenazas por parte de la "barra" es aquello que Alabarces (2014) identificó como el rol que esta se autoasigna como guardianes de la identidad del club. Ese papel los habilita a exigir a jugadores y entrenadores mayor esfuerzo en la cancha, exigencia que se hace a través de prácticas generalmente violentas.

Ahora bien, si a esta categoría le sumamos los hechos que registran agresiones a los árbitros, por un lado, y agresiones hacia dirigentes por otro, se convierte en la categoría con más peso, con el $27 \%$ de los casos totales. El agrupamiento de estas tres categorías se justifica desde el punto de vista conceptual, en tanto todas registran las agresiones de parte hacia actores 
que podemos considerar como "protagonistas" del espectáculo futbolístico desde una lectura más tradicional (Segura et al. 2018). No son peleas entre aficionados, ni de estos con la policía, sino agresiones cuyo destinatario son aquellos actores que a priori no tienen a la violencia física como parte de su repertorio de prácticas, o al menos que no la reivindican. Además de las explicaciones para comprender este tipo de violencia, ligadas a la tradición, por un lado, y a la autopercepción de los hinchas como únicos guardianes de la identidad del club por el otro, no podemos dejar de echar mano de la prohibición del público visitante, política vigente en los estadios argentinos desde el año 2007 para las categorías de Ascenso y desde 2013 para la Primera División.

Gráfico 6: Peleas entre hinchas y rivales, y agresión de hinchas a protagonistas de Primera División, 2006-2017

14

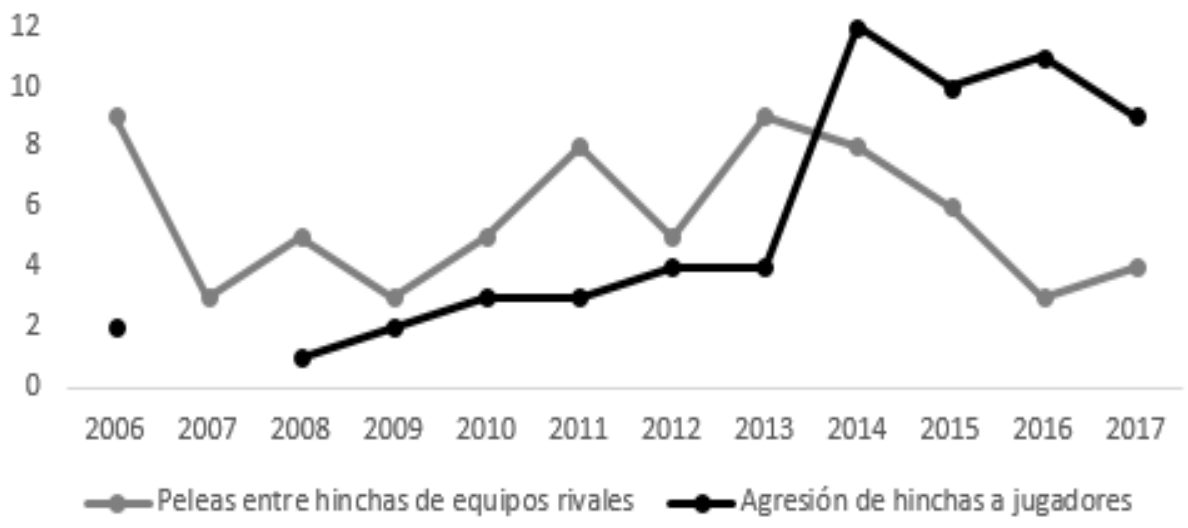

Fuente: Elaboración propia.

La interdicción de la parcialidad visitante implicó la eliminación física de ese "otro" que constituía la referencia central de rivalidad para los aficionados. El público argentino quedó, a partir de allí, hablando solo, en el vacío, o incluso hablándose a sí mismo (Alabarces 2014, Bundio 2013). En el mejor de los casos, la referencia al rival se realiza mediada por la televisión: hinchas insultando, ridiculizando, desafiando o gozando a rivales que no están presentes físicamente, sino que reciben el mensaje por la pantalla televisiva. Para graficar cómo ha impactado la prohibición del visitante en el aumento de esta dinámica, hicimos el ejercicio de tomar solamente los partidos de Primera División, categoría donde el visitante fue prohibido en el 2013, y comparar dos variables: las peleas entre hinchadas rivales y las agresiones a protagonistas, antes y después de la prohibición. Lo que notamos es que, mientras que las peleas entre hinchas rivales 
superan en número a las agresiones de hinchas a protagonistas durante todos los ańos que van desde 2006 hasta 2012, esta tendencia se invierte absolutamente a partir de 2013, año donde se inicia la prohibición del público visitante. Desde 2013 en adelante, en todos los años subsiguientes registramos más agresiones hacia jugadores, árbitros y dirigentes que peleas o agresiones entre hinchas de equipos rivales.

Un hecho impactante del relevamiento aparece en el año 2014. Por primera vez en la historia del fútbol argentino se registró el asesinato de un futbolista producto de una agresión. Ocurrió en el marco de un partido por la Liga de Ainogasta, en la provincia de La Rioja, cuando Franco Nieto recibió un piedrazo en la cabeza que le ocasionó la muerte. Su deceso no conmocionó a la estructura del fútbol profesional, no tuvo casi rebote en los medios de comunicación nacionales, ni tampoco sirvió para incomodar a los funcionarios de seguridad deportiva. La nula relevancia de la competencia donde participaba Franco Nieto, la histórica subalternidad del fútbol del interior y la no afiliación del jugador al Sindicato de Futbolistas, conspiraron para que su muerte no fuese tomada como aquel límite que no se puede cruzar. Sin embargo, el asesinato de Nieto sienta un precedente importante respecto a la ampliación de las formas que adquieren las violencias en el fútbol argentino.

Entre estos tres tipos de incidente que venimos de analizar, es decir, las disputas intrahinchadas, las clásicas peleas entre aficionados rivales y las agresiones a protagonistas del juego, se concentra el 70\% de los hechos de violencia relevados. Del resto de los incidentes identificados, aquella categoría que merece más atención es la de "peleas de hinchas con la policía" (que en la mayoría de los casos asume la forma de represión policial), que representa un aproximado de $14 \%$ de los hechos.

\section{REPRESION Y ENFRENTAMIENTOS CON LA POLICIA}

Los enfrentamientos de fanáticos con la policía han sido un hecho histórico del fútbol argentino (Archetti y Romero 1994, Galvani y Palma 2005) y la causa de un número significativo de muertes (Murzi, Sustas y Uliana 2015, Segura et al. 2018). Determinar la influencia policial en cada incidente es una tarea compleja, ya que por definición las fuerzas policiales tienen el rol de intervenir en los conflictos, con lo cual su participación podría verse sobrerrepresentada o subrepresentada según los datos obtenidos en el análisis.

Si bien nuestro relevamiento coincide con un amplio período donde existió la voluntad estatal de limitar la violencia policial, a partir de la 
prohibición del uso de armas en las manifestaciones sociales, por ejemplo (Kessler 2015), los estadios de fútbol siguieron siendo espacios donde el control de desórdenes se gestionó mediante el uso de represión. Si miramos solo los incidentes ocurridos en el marco de los partidos de fútbol, y en los espacios donde la policía tiene injerencia -dentro del estadio y en las inmediaciones-, la participación del personal policial asciende al 35\%. Y si acercamos aún más la lupa hacia la zona en la cual los agentes policiales se concentran -el operativo de seguridad-, la policía resultó involucrada, de una forma u otra, en el $58 \%$ de los hechos. No obstante, un aspecto estadísticamente relevante fue el descenso de la injerencia policial en los hechos que terminaron con víctimas fatales. Según las estadísticas del Departamento de Investigaciones de la ONG Salvemos al Fútbol (Murzi, Sustas y Uliana 2015) sobre el total de muertes del fútbol ocurridas entre 1992 y 2014, el 20\% se debieron a la represión policial. Esa cifra descendió sensiblemente si consideramos únicamente las muertes ocurridas en nuestro período de estudio a un $6 \%$.

Hechos centrales con participación policial en estos años analizados (2006 y 2017) fueron la muerte del aficionado de San Lorenzo, Ramón Aramayo, quien falleció tras un control de ingreso al estadio de Vélez Sarsfield en 2012. O el asesinato del simpatizante de Lanús, Martín Jerez, en junio de 2013, producto de una bala de goma policial tras una feroz represión en las inmediaciones del Estadio Único de La Plata, hecho que amplió la medida de prohibición del público visitante también para la Primera División. Entre los casos donde los agentes del orden son agredidos por grupos de aficionados hubo uno dramático en el estadio de Laferrere en marzo de 2015, cuando la policía fue atacada al intentar evitar que 200 hinchas ingresaran al estadio por la fuerza.

Así, el registro de todos estos hechos en sus diferentes categorías, nos permite identificar algunas tendencias en relación a los lugares donde han ocurrido los episodios identificados. Veamos cuáles son los espacios donde ocurren.

\section{LUGARES DE LOS HECHOS REGISTRADOS}

Una de los postulados de este artículo, amparado en investigaciones académicas previas (Garriga 2013, Cabrera 2015) y también en la evidencia de una creciente expansión del área de influencia de los dispositivos de seguridad y control, afirma que, en la última década, la violencia en el fútbol se autonomizó en gran medida del espacio geográfico del estadio. Pero, ¿cómo es posible hablar de violencia en el fútbol en hechos que ocurren desligados del espectáculo futbolístico? En la actualidad, no solo 
se identifica el lugar geográfico del hecho, sino también las motivaciones simbólicas que atravesaron el crimen (Murzi, Sustas y Uliana: 12).

En el análisis reciente de las muertes (Murzi, Sustas y Uliana 2015), el $24 \%$ de los casos, es decir, un cuarto de los hechos que terminaron con víctimas fatales, no ocurrió en los estadios ni en sus inmediaciones. Este antecedente nos sirvió de marco para la construcción de la variable "En el marco del partido" en nuestro relevamiento. Se trata de una variable dicotómica, y los resultados indican que el 33\% de los incidentes registrados ocurrieron fuera del marco de referencia de algún partido, lo que confirma en parte la hipótesis de una cierta autonomía de los hechos de violencia respecto del espectáculo futbolístico. Entre los incidentes que no ocurrieron en el marco de un partido, un tercio de ellos fueron ligados a peleas internas entre miembros o facciones de diferentes barras bravas. El restante, es decir dos tercios de ese 33\%, si bien fueron hechos alejados del espacio del estadio, tuvieron su origen en cuestiones futbolísticas, del orden de la competencia deportiva: amenazas y agresiones de hinchas a jugadores y dirigentes en domicilios, sedes de clubes o entrenamientos, peleas entre hinchas o hinchadas rivales, disturbios o destrozos de hinchas en festejos o conmemoraciones en la vía pública, entre otras formas de violencia.

Gráfico 7: Lugar donde ocurrieron los incidentes, 2006-2017

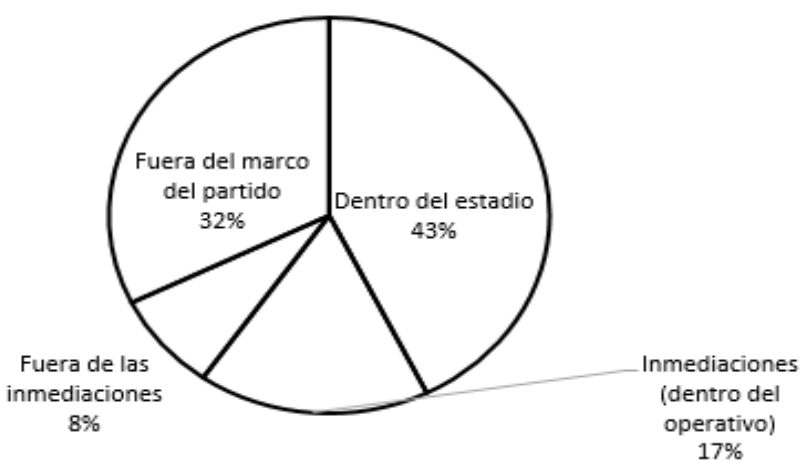

Fuente: Elaboración propia.

Sin embargo, la mayor cantidad de incidentes se produce aún con partidos de fútbol como marco de referencia. El 67\% de estos hechos estuvieron asociados a un encuentro futbolístico, y sobre ese total, el $63 \%$ de ellos ocurrió dentro del estadio, el $25 \%$ en las inmediaciones y el $12 \%$ restante fuera de las inmediaciones. La discriminación del espacio en que ocurrieron arroja un dato significativo para leerlo en función de 
la construcción de la seguridad deportiva. Del total de incidentes, menos de la mitad ocurrió dentro del estadio. Y si sumamos los ocurridos dentro del estadio y aquellos que tuvieron lugar en las inmediaciones, perímetro abarcado por el operativo de seguridad, obtenemos un $60 \%$ del total. El Gráfico 7 ayuda a ilustrar este panorama.

Esto equivale a decir que un poco más de la mitad de los incidentes ocurren en las áreas vigiladas y controladas por las fuerzas de seguridad. Pese al despliegue creciente de los mecanismos de control y al aumento de efectivos policiales, un alto número de incidentes se han registrado en estos espacios hiper vigilados.

Con todos estos datos estadísticos y sus interpretaciones podemos proponer una serie de conclusiones a modo de cierre sobre este relevamiento, sus inferencias y tareas pendientes, tanto para la investigación en ciencias sociales, como para el diseño, la implementación, la gestión y la evaluación de políticas públicas.

\section{CONCLUSIONES Y PENDIENTES}

Los casos que conforman nuestra base son considerados una población estadística de muestreo, en el sentido que no abarcan, de ninguna manera, la totalidad de los incidentes ocurridos en el período seleccionado, solamente aquellos que fueron reflejados en la prensa y que fueron identificados por los autores. Puede haber otros que, a pesar de haber sido registrados por algún medio, escaparon a nuestro esfuerzo de recolección. Además, para poder hablar de un conjunto exhaustivo de hechos deberíamos contar con todos los incidentes de violencia ocurridos, al menos en el perímetro del fútbol, empresa prácticamente imposible debido a que no existen mecanismos, ni instancias institucionales que hayan asentado públicamente los incidentes sucedidos en los miles de partidos jugados en la última década ${ }^{6}$. Todo esto para decir, que los datos aquí expuestos son solamente una muestra,

6 Esto solo sería posible en caso de que sea el Estado o la AFA quienes se encárguese rigurosamente de esa tarea. En Francia, por ejemplo, para los partidos que dependen de la Federación Francesa de Futbol a nivel amateur, son los árbitros quienes al finalizar cada encuentro registran en un informe diferentes prácticas y conductas del público y los jugadores previamente definidas por la Federación. Ese informe es elevado a un organismo de la propia Federación llamado "Observatorio de Comportamientos en el deporte", el cual nuclea la información y elabora informes anuales con el fin de generar políticas públicas. A lo largo de la temporada 2015-2016 el Observatorio identificó violencias en 10.997 partidos (el 1,4\%) sobre un total de más de 780.000 encuentros jugados. Fuente: informes internos de la FFF cedidos a estos autores. 
imperfecta, pero que permite inferir ciertas tendencias.

Al tomar los datos recabados para el período 2006-2017, observamos algunas tendencias claras. La primera es la confirmación de uno de nuestros postulados principales: los enfrenamientos y agresiones han ocurrido con mayor frecuencia entre hinchas con la misma camiseta que entre aficionados de equipos rivales. Esto obliga, por lo menos, a revisar los supuestos que estructuran las políticas públicas de seguridad deportiva en Argentina. La prohibición del visitante, implementada en forma progresiva no ha logrado terminar con las prácticas violentas, sino que estas se redireccionaron, mutaron, se transformaron, y encontraron nuevos objetivos para manifestarse.

Eliminados "los contrarios" del escenario de los estadios, los únicos representantes del equipo rival que quedaron desde el 2007 en el Ascenso y desde 2013 como marco general, a excepción de la Copa Argentina, son los jugadores, el cuerpo técnico y el puñado de dirigentes que acompaña a cada club visitante. Y precisamente, es sobre estos actores donde registramos un incremento en la cantidad de agresiones en los últimos años. Ahora bien, es curioso ver que las agresiones han apuntado tanto hacia los protagonistas adversos, como hacia aquellos del club de los agresores. Estos episodios permiten inferir que el factor de rendimiento deportivo no debe abandonarse como una de las explicaciones a las violencias. En los últimos años, numerosos futbolistas y árbitros fueron agredidos, y la lista incluye registros de más de 40 clubes donde esto ha sucedido. Si bien estas agresiones por lo general no tienen consecuencias fatales y durables para la integridad física de las víctimas, aunque a veces puede acontecer como lo fue el episodio trágico del jugador Nieto en La Rioja, aportan elementos a la creación y reproducción de atmósferas de violencias.

Las "barras bravas", sindicadas como los últimos responsables de la violencia, aparecen en un poco más del $60 \%$ de los episodios identificados. La participación de otros protagonistas del espectáculo confirma la aseveración del antropólogo José Garriga (2013), cuando sostiene que todos los actores del fútbol recurren a las prácticas violentas, en la medida en que la violencia parece ser un recurso legítimo en el mundo del fútbol argentino. La violencia en el fútbol se manifiesta muchas veces en partidos de fútbol de salón o en divisiones juveniles, alejados de los focos de los medios de prensa.

Los datos verifican, además, otra tendencia, aunque no pueda decirse categórica, presenta su relevancia. La violencia ha tendido en esta última década a tomar cierta autonomía del espacio geográfico del estadio, para 
manifestarse en lugares donde la vigilancia es débil o directamente no existe. Un tercio de los episodios que se inscriben dentro de la violencia en el fútbol ocurren en ámbitos alejados del estadio.

Necesitamos agregar, también, la dificultad de aclarar los hechos cuando los excesos son cometidos por agentes del Estado. Al inicio de 2017 se hizo un intento por permitir el regreso de los aficionados visitantes a los estadios, pero en el estadio de Lanús, los hinchas de River Plate recibieron una serie de maltratos por parte de los agentes del orden. En general, los medios no clasifican estos hechos como violencia, pero volvemos a insistir sobre la generación de ambientes que propician climas agresivos.

El tratamiento que se ha dado a las respuestas públicas se ha configurado desde los ańos 1980 a partir de un enfoque meramente policial del problema. Algo que, como diversas investigaciones han mostrado, lejos de resolver el problema parece haberlo agravado. En otros países, el problema de aficionados violentos ha sido encarado por diferentes ejes de acción. En algunos casos se ha recurrido al trabajo social como contraparte de las sanciones (Segura y Murzi 2015). Es cierto que cada contexto nacional y local es diferente de otros, pero el ingreso a las "barras bravas" también puede ser visto como un espacio donde miles de jóvenes procuran sentidos y emociones. Por lo tanto, el enfoque policial es limitado como herramienta del Estado. Podemos afirmar, inclusive, que no hay evidencia que contradiga que el trabajo social no funciona, por el simple hecho que no se ha implementado, y por lo tanto, evaluado, alguna política pública destinada a la prevención en este problema.

Finalmente, en todos estos datos presentados estamos hablando de violencias visibles, es decir, registradas por los medios bajo el rótulo de violencia en el fútbol. Empero, el problema de las violencias invisibles, es decir todos los actos que propician situaciones, climas, ambientes y canales para que la violencia se exprese parecen quedar en un segundo plano. Es ahí donde la tarea de investigación debe profundizar los orígenes y causas de las expresiones visibles e invisibles a los ojos de los medios de comunicación. 


\section{REFERENCIAS}

Alabarces, P. (2004). Crónicas del Aguante. Buenos Aires: Capital Cultural. . (2014). Héroes, Machos y Patriotas: El fútbol entre la Violencia y los Medios. Buenos Aires: Aguilar.

Aragón, S. (2007). Los Trapos se Ganan en Combate. Buenos Aires: Antropofagia.

Archetti, E. (1999). Masculinities: Soccer, Polo and the Tango in Argentina. Michigan: Berg.

Archetti, E. y Romero, A. (1994). Death and Violence in Argentinian Soccer. En Giulianotti, R., Bonney, N. y Hepworth, N. (Eds.), Soccer, Violence and Social Identities. Londres: Routledge.

Bergés, M. (2015). Sobre el Rafa Di Zeo, Mauricio Macri y la 12. En Nizzardo, M. y Berges, M. (Eds.), Salvemos al Futbol. Buenos Aires: Dunken.

Bourdieu, P. y Passeron, J. C. (2001). La Reproducción. Elementos para una Teoría del Sistema de Enseñanza. Ciudad de México: Fontamara.

Bundio, J. (2013). Redes Negativas: El Pequeño Mundo de las Hinchadas de Fútbol. Redes, 24 (2): 109- 134.

. (2014). Redes de Rivalidades y Alianzas entre Grupos de Simpatizantes en Argentina. Revista del Museo de Antropología, 7 (2), 379-386.

Cabrera, N. (2013). De Corporalidades Masculinas, Aguantadoras y Populares. Violencia, Identidad y Poder en la Hinchada del Club Atlético Belgrano. En Garriga, J. (Ed.), Violencia en el Fútbol. Buenos Aires: Godot.

Cabrera, N. (2015). Gramsci, Bebote y Bullrich. La Papa que Calienta y no Quema. Voces en el Fenix, 58, 102-109.

Carrión, F. (2014). Violencia en el Fútbol: Razones de una Sinrazón. En

Carrión, F. y Rodríguez, J. (Eds.), Luchas Urbanas Alrededor del Fútbol. Quito: 5ta Avenida Editores. 
Carrozza, P. (2015). Yo No Soy Como Esos. Buenos Aires: Planeta.

Castro, J. (2013). El Carnaval y el Combate Hacen el Aguante en una Barra Brava. Revista Colombiana de Sociología, 36 (1), 77-92.

Cohen, S. (1972). Moral Panics and Folk Devils. Londres: MacGibbon \& Kee.

Conde, M. (2005). La Invención del Hincha en la Prensa Deportiva. En Alabarces, P. (Ed.), Hinchadas. Buenos Aires: Prometeo.

Czesli, F. (2013). Apuntes sobre la Identidad en la Hinchada de Platense. En Garriga, J. (Ed.), Violencia en el fútbol. Buenos Aires: Godot.

D’Angelo, N. (2012). La Nueva Conflictividad de las Barras Bravas en Argentina: Una Lectura a la Luz de la Teoría de Redes. Revista de Investigación Social, 7 13, 55-75.

Duke, V. y Crolley, L. (2001). Football, Politicians and the People: Populism and Politics in Argentina. The International Journal of the History of Sport, 18 (3), 93-116.

Dunning E (2000) Towards a Sociological Understanding of Football Hooliganism as a World Phenomenon, European Journal on Criminal Policy and Research, V 8 (2): 141-162.

Dunning, E. Murphy, P. y Williams, J. (1986). Spectator Violence at Soccer Matches: Towards a Sociological Explanation. En Elias, N. y Dunning, E. (Eds.), Quest for Excitement. Oxford: Blackwell.

Foucautl, M. (2000). Defender la Sociedad. México: Fondo de Cultura Económica.

Frydemberg, J. (2012). Historia Social del fútbol. Buenos Aires: Siglo XXI. Gaffney, C. (2009). Stadiums and Society in Twenty-First Century Buenos Aires. Soccer \& Society 10 (2), 160-182.

Galvani, M. y Palma, J. (2005). La Hinchada de Uniforme. En Alabarces, P. (Ed.), Hinchadas. Buenos Aires: Prometeo.

Garland, D. (2005). La Cultura del Control: Crimen y Orden Social en la Sociedad Contemporánea. Barcelona: Gedisa. 
Garriga, J. (2006). Haciendo Amigos a las Piñas. Buenos Aires: Prometeo. . (2013). Cartografías de la(s) Violencia(s). En Garriga, J. (Ed.), Violencia en el Fútbol. Buenos Aires: Godot.

Garriga, J., Murzi, D. y Rosa, S. (2017). Enemigos Íntimos, Anfibia, junio. Disponible en http://www.revistaanfibia.com/ensayo/enemigosintimos/ [05-06-2018]

Galtung, J. (1969). Violence, Peace, and Peace Research. Journal of Peace Research, 6 (3), 167-191.

Gil, G. (2007). Hinchas en Tránsito. Mar del Plata: EUDEM.

Kessler, G. (2008). El Sentimiento de Inseguridad: Sociología del Temor al Delito. Buenos Aires: Siglo XXI.

. (2015). Controversias sobre la Desigualdad: Argentina, 2003-2013. Buenos Aires: Fondo de Cultura Económica.

Hall, S. (1978). The Treatment of "Football Hooliganism" in the Press. En Ingham, R., Hall, S., Clarke, J., Marsh, P. y Donovan, J. (Eds.), "Football Hooliganism": The Wider Context. Londres: Inter-Action Imprint.

Hollanda, B. (2017). Torcidas, Hinchadas e Barras: A Problemática Torcedora em Escala Continental. En Hollanda, B. y Rodríguez, O. (Eds.), Torcidas Organizadas na América Latina. Rio de Janeiro: 7 Letras.

Ingham, R. (1978). Soccer Hooliganism. Londres: Inter-Action Imprint.

Lasswell, H. (1951). The Policy Orientation. En Lerner, D. y Lasswell, The Policy Sciences. Recent Develoments in Scope and Method. Stanford: Stanford University Press.

Lindblom, C. (1959). The Sciences of Muddling Through. Public Administration Review, 19 (2), 79-88.

Marsh, P. (1978). Aggro: The Illusion of Violence. Londres: Dent.

Moreira, V. (2005). Trofeos de Guerra y Hombres de Honor. En Alabarces, P. (Ed.), Hinchadas. Buenos Aires: Prometeo. 
. (2012). Juego Electoral y Relaciones Políticas en el Fútbol Argentino. Questóes \& Debates, 57 (1), 127- 149.

Murzi, D. (2011) Hooligan ou Businessman? Portrait de Supporters de Soccer Violents en Argentine. Tesis de Maestría (Sociología), Ecole des Hautes Études en Sciences Sociales, París, Francia.

Murzi, D., Uliana, S. y Sustas, S. (2011). El Fútbol de Luto. Análisis de los Factores de Muerte y Violencia en el Fútbol Argentino. Godio, M y Uliana, S. (Comps), Fútbol y Sociedad. Prácticas Locales e Imaginarios Globales. Buenos Aires: EDUNTREF.

Murzi, D. y Segura-Trejo, F. (2014). Violences dans les Stades en Argentine: La Place des «Barras-Bravas» et la Réaction Citoyenne. En Busset, T., Besson, R. y Jaccoud, C. (Eds.), L'autre Visage du Supportérisme. Berne: Peter Lang.

Murzi, D., Sustas, S. y Uliana, S. (2015). La Violencia en el Fútbol desde las Ciencias Sociales. En Nizzardo, M. y Bergés, M. (Eds.), Salvemos al Futbol. Buenos Aires: Dunken.

Romero, A. (1985). Deporte, Violencia y Política. Buenos Aires: Centro Editor de América Latina.

. (1986). Muerte en la Cancha. Buenos Aires: Editorial Nueva América.

. (1994). Las Barras Bravas y la Contrasociedad Deportiva. Buenos Aires: Nueva América.

Sain, M. y Rodríguez, J. (2014). Los Actores y la Seguridad en el Fútbol. En Carrión, F. y Rodríguez, J. (Eds.), Luchas Urbanas Alrededor del Fútbol. Quito: 5ta Avenida Editores.

Segura M. Trejo, F. (2013). Ritualización y Mercantilización de la Violencia en el Fútbol: Elementos Comunes y Diferencias entre las Barras de Argentina y México. Documento de trabajo de la División de Administración Pública, 267. Ciudad de México: CIDE.

Segura M. Trejo, F. y Murzi, D. (2015). ¿Gestión de la Violencia en el Fútbol? Perspectivas Críticas sobre Inglaterra y Bélgica. Revista de Gestión Pública, 4 (1), 65- 106. 
Segura M. Trejo, F., Murzi, D. y Nassar, B. (2018). Violence and Death in the Argentinean Aoccer in the New Millennium. Who is Involved and What is at Stake. International Review for the Sociology of Sport. https:// doi.org/10.1177/1012690217748929

Sodo, J. (2013). De la Violencia a los Ambientes de Violencia: Entre el Doble Discurso de los Hinchas y el Doble Reduccionismo Mediático. En Garriga, J. (Ed.), Violencia en el Fútbol. Buenos Aires: Godot.

Spaiij, R. (2006). Understanding Soccer Hooliganism. Amsterdam: Amsterdam University Press.

Sustas, S. (2013). Las Violencias Sentenciadas. En Garriga, J. (Ed.), Violencia en el Fútbol. Buenos Aires: Godot.

Szlifman, J. (2010). La Fiesta Que No Fue. Un análisis sobre los Medios de Comunicación y la Violencia en el Fútbol Argentino. Buenos Aires: EFDeportes.

Taddei, R. (2016). La Invención de la Violencia (de las Hinchadas de Buenos Aires). Antipoda Revista de Antropología y Arqueología, 24, 1533.

Taylor, I. (1971). Soccer Mad: A Speculative Sociology of Soccer Hooliganism. En Dunning, E. (Ed.), Sociology of Sport. Londres: Cass.

Tsoukala, A. (2009). Soccer Hooliganism in Europe: Security and Civil Liberties in Balance. Londres: Palgrave.

Vigarello, G. (2000). Historie du Viol : XVII -XX siècles. Paris : Points Histoires.

Warin, P. (1999). Les 'Ressortissants' dans les Analyses des Politiques Publiques. Revue Française de Sciences Politiques, 49 (1), 103-121.

Recibido: 07-04-2018 Aceptación de la versión final: 30-05-2018 